EESTI NSV TEADUSTE AKADEEMIA TOIMETISED, 28. KOIDE KEEMIA, 1979, NR. 1

ИЗВЕСТИЯ АКАДЕМИИ НАУК ЭСТОНСКОЙ ССР. ТОМ 28 ХИмИЯ, 1979, № 1

P. ВЕСКИ, Н. ФИЛИМОНОВА, Евгения БОНДАРЬ,

T. ЛУМНСТЕ, А. ФОМИНА

\title{
ИССЛЕДОВАНИЕ ОРГАНИЧЕСКОГО ВЕЩЕСТВА ДИКТИОНЕМОВОГО СЛАНЦА ОКИСЛЕНИЕМ АЗОтноЙ КИСЛОТОЙ
}

\author{
(Представлена О. Эйзеном)
}

Диктионемовые сланцы представляют собой темно-коричневые сланцеватые аргиллиты с содержанием в среднем $15 \%$ органического вещества (OB), из которого при полукоксовании в алюминиевой реторте образуется около $20 \%$ смолы [']. Смола полукоксования диктионемовото сланца характеризуется низким содержанием алканов и алкенов, их суммарное содержание, по данным $\left[{ }^{2-4}\right]$, составляет около $1 \%$ на ОВ. Сравнение длины $\boldsymbol{H}$-алкановых цепей $\left(\mathrm{C}_{5}-\mathrm{C}_{20}\right)$ дебитуминизированного сланца и его битумоида $\left(\mathrm{C}_{10}-\mathrm{C}_{36}\right)$ показывает, что источники их происхождения различны [5]. Высказывалась возможность образования длинноцепочечных станавливающих бактерий [ $\left.{ }^{6}\right]$.

Содержание ароматических соединений, идентифицированных в смоле полукоксования диктионемового сланца, значительно выше содержания $H$-алканов и алкенов $\left[{ }^{2-4}\right]$, но они не несут равнозначной с последними информации об исходной структуре ОВ вследствие возможного их образования в результате вторичных реакций.

Выявлено также, что для диктионемового сланца характерно непостоянство выхода гуминовых кислот [7] и битумоида, а также выхода и состава смолы полукоксования [6].

При гидролизе диктионемового сланца были идентифицированы в незначительных количествах аминокислоты и углеводы [8]. Что касается образующихся при окислении диктионемового сланца органических кислот, то количественных данных об этом в литературе нет. Известно только, что при окислении перманганатом калия в щелочной среде образуются в основном алифатические дикарбоновые кислоты: щавелевая и высшие гомологи янтарной кислоты. Из алифатических монокарбоновых кислот были идентифицированы первые члены гомологического ряда, из бензолкарбоновых - бензойная (в следах) [ $\left.{ }^{9}\right]$.

Об образовании бензолкарбоновых кислот при окислении диктионемового сланца азотной кислотой было сообщено нами ранее [10]. Ниже приводятся данные о выходе и составе бензолкарбоновых и алифатических кислот в зависимости от глубины окисления.

\section{Обработка азотной кислотой при комнатной температуре}

Исследование проводилось на средней пробе диктионемового сланца, отобранной из северной части карьера Маарду Эстонской ССР в марте 1975 г. сектором обогатительных процессов Института химии АН ЭССР (Р. Кох, В. Ахелик). Характеристика пробы приводится в табл. 1. 
Выход битумоида А (в виде эфирного и ацетонового экстрактов) составил $2,2 \%$ от ОВ. После обработки $10 \%$-ной соляной кислотой было извлечено дополнительно 1,0\% битумоида. Выход гуминовых кислот, по методике $\left[{ }^{12}\right]$, составил $3,0 \%$ от ОВ.

С целью удаления части растворимых в азотной кислоте минеральных веществ и облегчения разделения продуктов последующего окисления, исходный сланец, измельченный до 0,1 мм, обрабатывался в течение 24 ч $20 \%$-ной азотной кислотой при комнатной температуре и соотношении $3,5 \Omega$ кислоты на 1 ке сланца. После вышеуказанной обработки

Таблица 1

Характеристика пробы диктионемового сланца месторождения Маарду, \% *

\begin{tabular}{l|c|c|c|c|c|c|c|c|c|c}
\hline \multicolumn{1}{c}{ Наименование } & $\mathrm{A}^{\mathrm{c}}$ & $\begin{array}{c}\mathrm{CO} \\
2 \\
\text { минер. }\end{array}$ & $\mathrm{OB}$ & $\mathrm{S}_{\text {общ. }}$ & $\mathrm{C}^{\mathrm{r}}$ & $\mathrm{H}^{\mathrm{r}}$ & $\mathrm{N}^{\mathrm{r}}$ & $\mathrm{S}^{\mathrm{r}}$ & $\mathrm{O}^{\mathrm{r}}$ & $\mathrm{H} / \mathrm{C}$ \\
\hline $\begin{array}{l}\text { Исходный сланец } \\
\text { Сланец, обработан- }\end{array}$ & 0,2 & 15,3 & 3,2 & 74,7 & 7,6 & 1,9 & 2,5 & 13,3 & 1,2 \\
$\begin{array}{l}\text { ный } 20 \% \text {-ной азот- } \\
\text { ной кислотой }\end{array}$ & $-19,2$ & $-18,9$ & 0,5 & 67,2 & 7,2 & $\underbrace{}_{25,6}$ & 1,3
\end{tabular}

* ОВ сланцев и элементный состав рассчитаны на основе [11], элементный состав

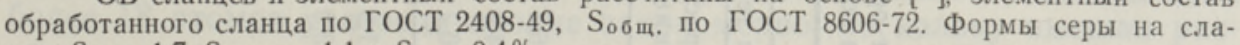

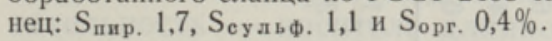

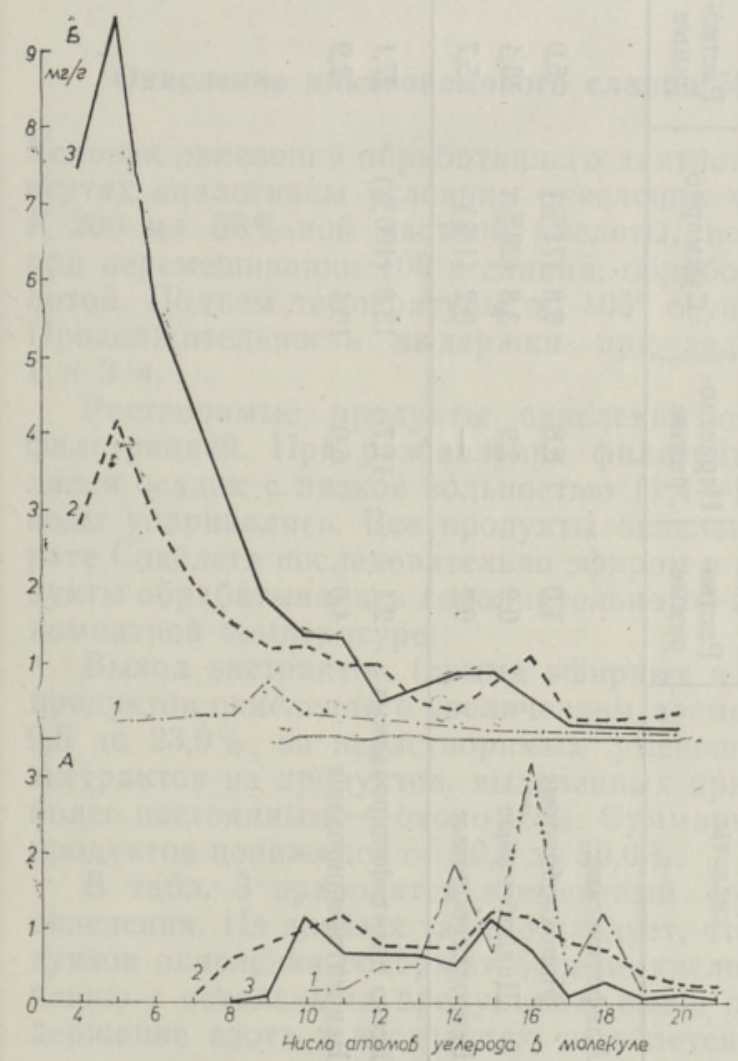

3 ENSV TA Toimetised. K 11979 суммарное содержание гетероатомов (N, S и O) в элементном составе ОВ увеличилось по сравнению с исходным от 17,7 до $25,6 \%$ (табл. 1), что объясняется легкостью окисления и нитрования ОВ сланца. Обработанный сланец и остаток упаривания фильтрата и промывных вод экстрагировались ацетоном в аппарате Сокслета. Выход экстрактов, соответственно, 10,9 (золы нет) и $7,7 \%$ (A с $9,8 \%$, за счет нитратов) от ОВ сланца. Экстракты дистиллировались, метилировались диазометаном и хроматографировались в усло-

Рис. 1. Выход моно- $(A)$ и дикарбоновых (Б) кислот от органического вещества диктионемового сланца при обработке его $20 \%$-ной азотной кислотой при комнатной температуре $(1)$; при окислении $58 \%$-ной азотной кислотой только с подъемом температуры до $105^{\circ} \mathrm{C}$ (2) и окнслении при $105^{\circ} \mathrm{C}$ в течение $3 थ(3)$. 


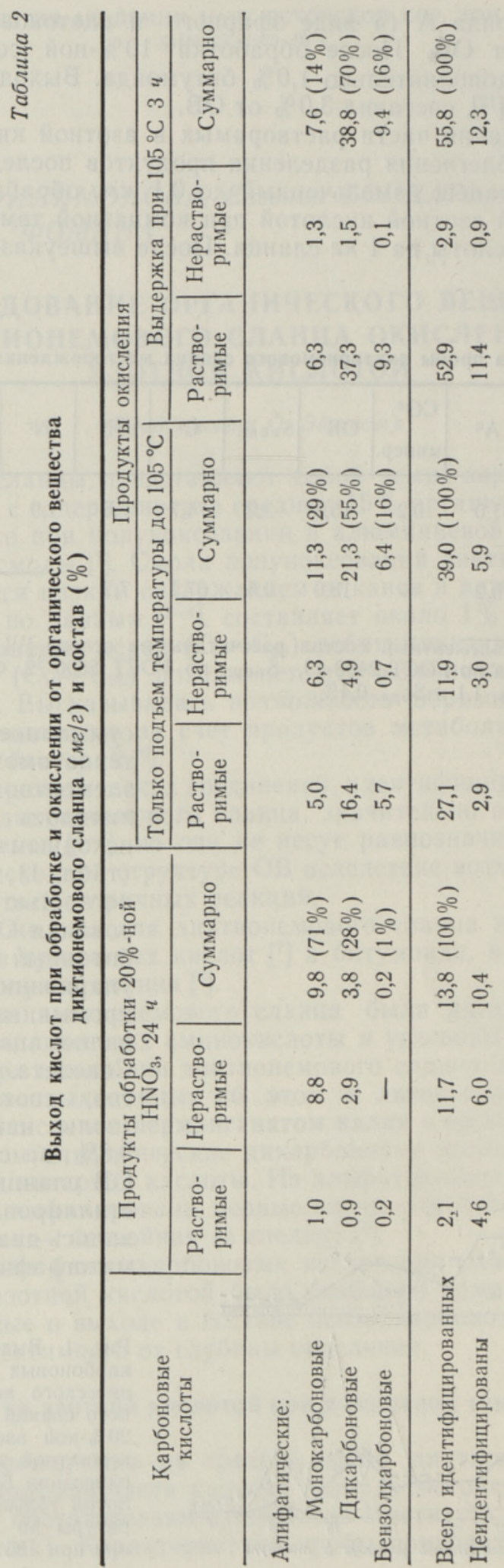


виях $\left[{ }^{10}\right]$. Выход и групповой состав кислот обработки приводятся вместе с продуктами окисления в табл. 2, а распределение моно- и дикарбоновых кислот - на рис. 1.

Необходимо сразу отметить, что в условиях обработки и выделения экстрактов низкомолекулярные кислоты битумоида извлекаются и определяются вместе с кислотами, полученными при мягкой окислительной деструкции сланца.

Состав кислот был следующий: алифатических монокарбоновых -71 , дикарбоновых - 28 и бензолкарбоновых - только $1 \%$. Монокарбоновые представлены в основном кислотами $\mathrm{C}_{14}, \mathrm{C}_{16}, \mathrm{C}_{18}$, с максимумом содержания $\mathrm{C}_{16}$. Все идентифицированные четные жирные кислоты характерны для сине-зеленых водорослей [13] - основного источника органического вещества горючих сланцев, а также и для бактериальных липидов [14].

В отличие от аналогичных объектов $\left[{ }^{15-17}\right]$, дикарбоновые кислоты из диктионемового сланца представлены практически одной азелаиновой $\left(\mathrm{C}_{9}\right)$ кислотой, что можно объяснить разрывом при окислении двойной связи $49-10$ распространенных в природе ненасыщенных кислот, таких, как $\mathrm{C}_{14: 1}, \mathrm{C}_{18: 1}, \mathrm{C}_{18: 2}, \mathrm{C}_{18: 3}$, или их производных. Произошел ли этот разрыв во время обработки азотной кислотой или раньше, можно установить при анализе кислот битумоида.

Отсутствие в продуктах обработки диктионемового сланца (мягкое окисление) алифатических моно- и дикарбоновых кислот с длиной цепи более 18 атомов углерода вполне закономерно, поскольку высшая растительность - носитель длинноцепочечных структур - во время отложения данного сланца отсутствовала.

\section{Окисление диктионемового сланца $58 \%$-ной азотной кислотой}

Условия окисления обработанного диктионемового сланца были в общих чертах аналогичны условиям окисления концентрата ОВ кукерсита $\left[{ }^{18}\right]$. К 200 мл 58\%-ной азотной кислоты, подогретой до $60^{\circ}$, прибавляли при перемешивании 100 г сланца, обработанного $20 \%$-ной азотной кислотой. Подъем температуры до $105^{\circ}$ осуществлялся в течение 50 мин. Продолжительность выдержки при заданной температуре: нулевая, 1 и 3 ч.

Растворимые продукты окисления отделялись от нерастворимых фильтрацией. При разбавлении фильтрата промывными водами выделялся осадок с низкой зольностыо $(1,4-1,9 \%)$. Фильтрат и промывные воды упаривались. Все продукты окисления экстрагировались в аппарате Сокслета последовательно эфиром и ацетоном. Нерастворимые продукты обрабатывались дополнительно $1-2 \%$-ным раствором щелочи при комнатной температуре.

Выход экстрактов (сумма эфирных и ацетоновых) из растворимых продуктов окисления с увеличением времени окисления увеличивался с 9,5 до $23,9 \%$, из нерастворимых уменьшался с 49,6 до $3,8 \%$. Выход экстрактов из продуктов, выделенных при разбавлении фильтрата, был более постоянным - около $10 \%$. Суммарный выход всех перечисленных продуктов понижался от 80,1 до $59,0 \%$.

В табл. 3 приводится элементный состав продуктов трехчасового окисления. Из данных табл. 3 следует, что экстракты растворимых продуктов окисления содержат больше кислорода и гетероатомов, по сравнению с остальными продуктами, выше для них и отношение Н/C. Содержание азота в экстрактах колеблется в пределах 4,2-5,7\%. Повы- 
таблица 3

Элементный состав экстрактов продуктов трехчасового окисления

\begin{tabular}{c|c|c|c|c|c|c}
\hline Наименование & $\mathrm{A}^{\mathrm{c}}, \%$ & $\mathrm{C}$ & $\mathrm{H}$ & $\mathrm{N}$ & $\begin{array}{c}\mathrm{O} \text { и др. } \\
\text { гетеро- } \\
\text { атомы }\end{array}$ & $\begin{array}{c}\mathrm{H} / \mathrm{C} \\
\text { ато- } \\
\text { марное }\end{array}$ \\
\hline
\end{tabular}

Растворимые продукты:

эфирный экстракт

ацетоновый экстракт

Нерастворнмые продукты:

эфирный экстракт

ацетоновый экстракт

Продукты, выделенные при разбавлении фильтрата:

эфирный экстракт ацетоновый экстракт

$\begin{array}{llllll}0,5 & 46,4 & 5,0 & 4,2 & 44,4 & 1,3 \\ 2,3 & 44,3 & 4,7 & 8,6 & 42,4 & 1,3 \\ & & & & & \\ - & 56,9 & 5,7 & 5,7 & 31,7 & 1,2 \\ 0,6 & 55,2 & 5,0 & 5,4 & 34,4 & 1,1 \\ & & & & & \\ & & & & & \\ - & 53,8 & 5,0 & 5,4 & 35,8 & 1,1 \\ - & 53,6 & 4,6 & 5,4 & 36,4 & 1,0\end{array}$

шенное содержание его в ацетоновом экстракте растворимых продуктов обусловлено растворенными в ацетоне нитратами.

Данные табл. 2 свидетельствуют о том, что основное количество идентифицированных кислот концентрируется в растворимых продуктах окисления и прямо зависит от продолжительности последнего. Аналогичная зависимость наблюдается и для суммарного количества образовавшихся при окислении ди- и бензолкарбоновых кислот, в то время, как количество монокарбоновых кислот убывает с увеличением продолжительности окисления. Что касается компонентного состава монокарбоновых кислот окисления, то, в сравнении с кислотами обработки, он значительно изменяется в сторону увеличения содержания кислот с меньшим числом атомов углерода в молекуле (рис. $1, A)$. Укорочение углеродной цепи наблюдается и для дикарбоновых кислот (рис. 1, Б).

Полученный выход дикарбоновых кислот из диктионемового сланца ( 38,8 мг/2, или $3,9 \%$ от ОВ) значительно ниже, по сравнению с выходом в технологических (жестких) условиях их получения из керогена кукерсита (свыше 30\% [19]). Это показывает, что доля алифатических и алициклических структур в ОВ диктионемового сланца значительно меньше, а доля лабильных к окислению структур, разлагающихся до $\mathrm{CO}_{2}$ и воды, больше, чем в ОВ кукерсита.

Жесткие условия окисления требовались для выяснения роли ароматических структур в ОВ диктионемового сланца. Согласно данным табл. 2, бензолкарбоновые кислоты составляют $16 \%$ от идентифицированных компонентов. Максимальный выход составил 9,4 мг/2, или $0,94 \%$ от ОВ сланца. Выход и состав кислот приводятся в табл. 4. Наибольшим было содержание бензойной кислоты. Поскольку она легко теряется в ходе подготовки проб к анализу, то можно предполагать, что ее действительный выход еще выше.

Трудно однозначно решить, из каких исходных структур образовались бензолкарбоновые кислоты. Однако, возможно, что бензойная кислота является продуктом деструкции моноалкилзамещенных ароматических структур. 1,3-, 1,4-, 1,3,5-Бензолкарбоновые кислоты не принадлежат к продуктам окисления конденсированных ароматических или смешанных арилоксиароматических структур, из которых могли образоваться (до половины по весу) 1,2-, 1,2,3-, 1,2,4-, 1,2,3,4-, 1,2,4,5-, 1,2,3,4,5и $1,2,3,4,5,6$-бензолкарбоновые кислоты. Последние, однако, в равной 
Таблица 4

Состав (\%) и выход бензолкарбоновых кислот от органического вещества диктионемового сланца (мг/100 г)

\begin{tabular}{|c|c|c|c|c|c|}
\hline \multirow{2}{*}{ Кислоты } & \multirow{2}{*}{$\begin{array}{c}\text { Положе- } \\
\text { ние кар- } \\
\text { боксиль- } \\
\text { ной группы }\end{array}$} & \multicolumn{2}{|c|}{$\begin{array}{c}\text { Подъем температуры } \\
\text { до } 105^{\circ} \mathrm{C}\end{array}$} & \multicolumn{2}{|c|}{ Окисление 3 u } \\
\hline & & Выход & Состав & Выход & Состав \\
\hline $\begin{array}{l}\text { Бензойная } \\
\text { Ортофталевая } \\
\text { Изофталевая } \\
\text { Терефталевая } \\
\text { Гемимеллитовая } \\
\text { Тримеллитовая } \\
\text { Тримезиновая } \\
\text { Меллофановая } \\
\text { Пиромеллитовая } \\
\text { Бензолпентакарбо- } \\
\text { новая } \\
\text { Меллитовая }\end{array}$ & $\begin{array}{c}1 \\
1,2 \\
1,3 \\
1,4 \\
1,2,3 \\
1,2,4 \\
1,3,5 \\
1,2,3,4 \\
1,2,4,5 \\
1,2,3,4,5 \\
1,2,3,4,5,6\end{array}$ & $\begin{array}{r}160 \\
85 \\
40 \\
85 \\
85 \\
20 \\
35 \\
65 \\
30 \\
25 \\
10\end{array}$ & $\begin{array}{r}26 \\
13 \\
6 \\
13 \\
13 \\
3 \\
5 \\
10 \\
5 \\
4 \\
\\
2\end{array}$ & $\begin{array}{r}330 \\
100 \\
65 \\
70 \\
115 \\
50 \\
80 \\
65 \\
50 \\
15 \\
\end{array}$ & $\begin{array}{r}35 \\
11 \\
7 \\
7 \\
12 \\
5 \\
9 \\
7 \\
5 \\
2\end{array}$ \\
\hline \multirow{2}{*}{ Меллитовая } & $1,2,3,4,5,6$ & 10 & 2 & следы & следы \\
\hline & Bcero: & 640 & 100 & 940 & 100 \\
\hline
\end{tabular}

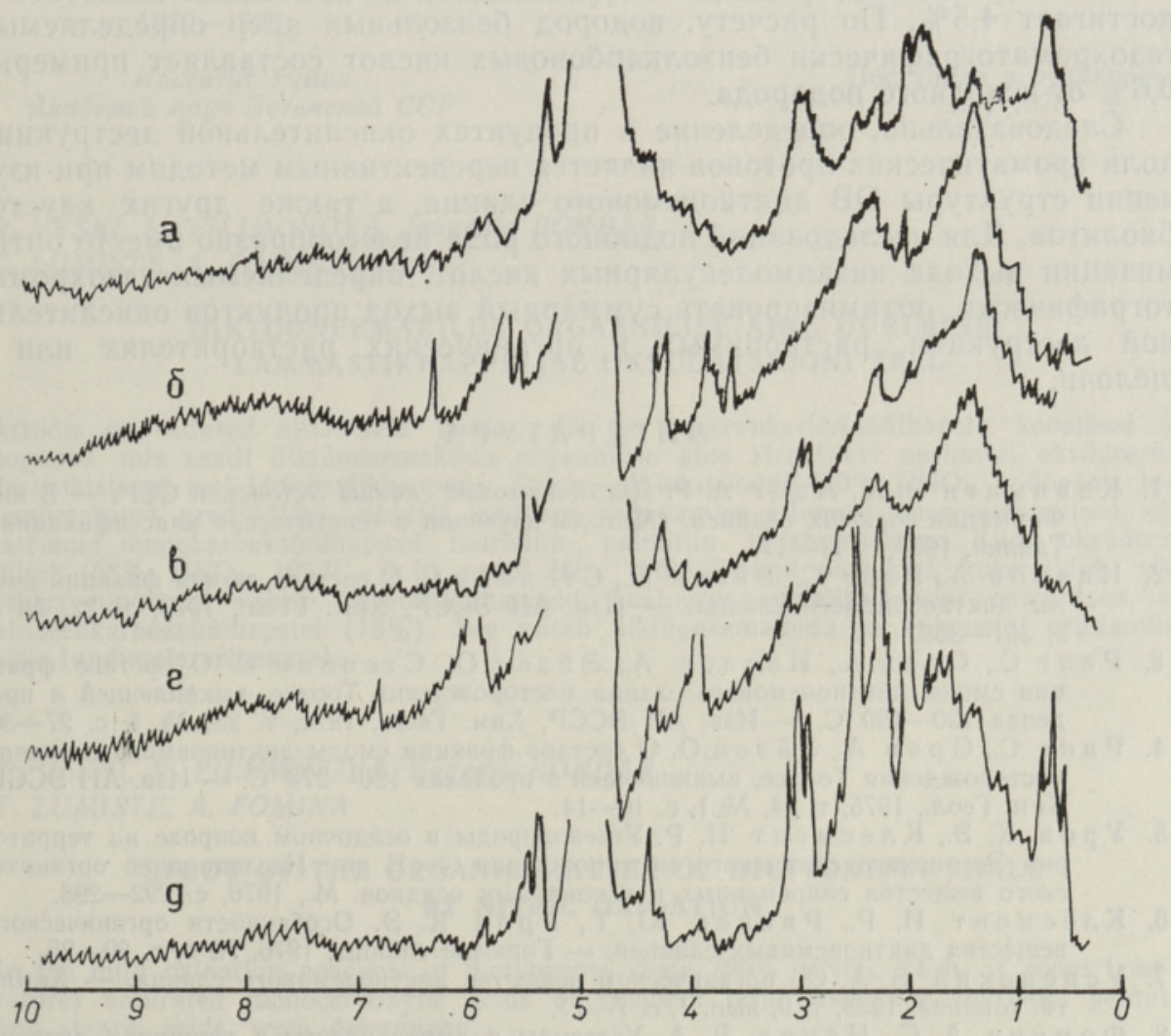

Рис. 2. Спектры протонного магнитного резонанса калиевых солей (обозначения см. в тексте): спектры сняты из $10 \%$-ных растворов в $\mathrm{D}_{2} \mathrm{O}$ при частоте $80 \mathrm{M \Gamma} u$ с внутренним эталоном ДСС (сигналы в середине спектра принадлежат HDO). 
степени вероятности могли образоваться и из алкилароматических, и из смешанных алициклоароматических структур.

Для установления наличия ароматических (оксиароматических) структур, помимо газохроматографического определения бензолкарбоновых кислот, продукты, полученные при окислении (трехчасовой опыт) и обработке, исследовались методом протонного магнитного резонанса (ПМР). Спектры были сняты на спектрометре TESLA BS 487 С при комнатной температуре и частоте $80 M \Gamma u$ из 10\%-ных растворов калиевых солей органических кислот (сумма эфирных и ацетоновых экстрактов) B $\mathrm{D}_{2} \mathrm{O}$.

Продукты обработки и окисления характеризуются спектрами ПМР, развитыми в основном в алифатической области (рис. 2). К алифатическим протонам были отнесены сигналы в области $\delta 0,4-3,5 \mu$. $\partial$., а к

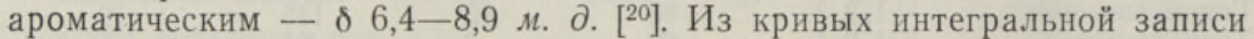
спектров было рассчитано содержание ароматических протонов - около $10 \%$ для экстрактов нерастворимых продуктов обработки $(a)$ и окисле-

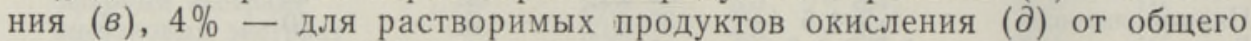
количества протонов. Содержание ароматических протонов в щелочном экстракте (2) и продуктах, осажденных при разбавлении фильтрата водой (б), выше и составляет, соответственно, 13 и 16\%. Итак, в среднем продукты трехчасового окисления содержат $8,6 \%$ ароматических протонов, что, в свою очередь, составляет $3,3 \%$ от водорода исходного сланца. В самых мягких условиях окисления последний показатель достигает $4,5 \%$. По расчету, водород бензольных ядер определяемых газохроматографически бензолкарбоновых кислот составляет примерно $0,6 \%$ от исходного водорода.

Следовательно, определение в продуктах окислительной деструкции доли ароматических протонов является перспективным методом при изучении структуры ОВ диктионемового сланца, а также других каустобиолитов. Для исследований подобного рода целесообразно вместо оптимизации выхода низкомолекулярных кислот, определяемых газохроматографически, оптимизнровать суммарный выход продуктов окислительной деструкции, растворимых в органических растворителях или в щелочи.

\section{ЛИ Т Е Р А Т У А}

1. К и в и м я ги Э. К., Л о ог А. Р. Диктионемовые сланцы Эстонской ССР. - В кн.: Формации горючих сланцев. (Методы изучения и генетическая классификация). Таллин, 1973 , с. $11-17$.

2. Ив а нов А., Р ан г С., Э й зен О., С те п н и н С. О составе легких фракций смолы диктионемового сланца. - Изв. АН ЭССР, Хим. Геол,, 1973, т. 22, № 4, c. $301-305$.

3. Ранг С., Орав А., Иванов А., Эйзен О., С те пнин С. О составе фракции смолы диктионемового сланца месторождения Тоолсе, выкипающей в пределах $120-190^{\circ} \mathrm{C}$. - Изв. АН ЭССР, Хим. Геол., 1974 , т. 23 , № 1, с. $27-30$.

4. Р а н Г С., О р а в А., Э й з е н О. О составе фракции смолы диктионемового сланца месторождения Тоолсе, выкипающей в пределах $190-270^{\circ} \mathrm{C}$. - Изв. АН ЭССР, Хим. Геол., 1975 , т. 24 , № 1, с. $10-14$.

5. У ров К. Э., Клесм ен Т И. Р. Углеводороды в осадочном покрове на территории Эстонского сланцевого месторождения. - В кн.: Исследование органического вещества современных и ископаемых осадков. М., 1976, с. 292-298.

6. Клесмент И. Р., Риккен Ю. Т., Уров К. Э. Особенности органического вещества диктионемовых сланцев. - Горючие сланцы, 1976, № 6, с. 20-25.

7. У сп ен ски й В. А. Об органическом веществе диктионемового сланца. - Химия тв. топлива, 1938 , т. 9 , вып. 1, с. $7-17$.

8. Фомина А. С., Напп а Л. А. Углеводы и аминокислоты в керогенах древних горючих сланцев. - Химия тв. топлива, 1967, № 1, с. 8-16.

9. Е р усенко В., Фомина А. К вопросу об окислительной деструкции керогена диктионемового сланца щелочным перманганатом калия. Сообщ. третье. - Изв, АН ЭССР, Сер. физ.-матем. и техн, н., 1966, т, 15, № 1, с. 106-112, 
10. Бондарь Е., Вески Р., Филимонова Н., Фомина А. Об ароматических структурах керогена диктионемового сланца. - Изв. АН ЭССР, Хим., 1978, т. 27 , № 3 , с. $176-178$.

11. Kirret, O., K $\mathrm{k}$ h, R., R ünda l, L. Maardu leiukoha diktüoneemakilda ja temas sisalduva kerogeeni keemilisest koostisest. - Изв. АН ЭССР, Сер. техн. и физ.-матем. н., 1959, т. VIII, № 4, с. 243-254.

12. Гинзбург А. И., Л а по А. В., Л ету ше в а И. А. Рациональный комплекс петрографических и химических методов исследования углей и горючих сланцев. Л., 1976.

13. Winters, K., Parker, P. L., B a a len, C. V. Hydrocarbons of blue-green algae: geochemical significance. - Science, 1969, v. 163, N 3866, p. 467-468.

14. Р убан Е. Л. Бактериальные липиды. - Изв. АН СССР, Сер. биол., 1974, № 2, c. $162-178$.

15. Burlingame, A. L., Simoneit, B. R. Analysis of the mineral entrapped fatty acids isolated from the Green River formation. - Nature, 1968, v. 218, p. $252-256$.

16. Simoneit, B. R., Burlingame, A. L. Carboxylic acids derived from Tasmanian tasmanite by extractions and kerogen oxidations. - Geochim. et cosmochim. acta, 1973, v. $37, \mathrm{~N} 3$, p. $595-610$.

17. Johns, R. B., O nder, O. M. Biological diagenesis: dicarboxylic acids in recent sediments. - Geochim. et cosmochim. acta, 1975, v. 39, N 2, p. 129-136.

18. Фомина А. С., Ильин А. И., Вески Р. Э. Окисление керогена кукерсита $58 \%$-ной азотной кислотой при атмосферном давлении. - В кн.: Горючие сланцы. Химия и технология. Таллин, Ин-т химии АН ЭССР, 1961 , вып. 4/5, с. 5-11.

19. Фомина А. С., Вески Р. Э., Мянник А. О. Технология химической переработки керогена горючих сланцев сапропелитового типа. - Химия тв. топлива, 1977, № 3, c. $170-174$.

20. Knight, S. A. Analysis of aromatic petroleum fractions by means of absorption mode carbon-13 N. M. R. spectroscopy. - Chemistry and Industry, 1967, v. 45, p. $1920-1923$.
Институт химии
Академии наук Эстонской ССР
Поступила в редакцию
13/I 1978

R. VESKI, N. FILIMONOVA, Jevgenia BONDAR,

T. LUMISTE, A. FOMINA

\section{DIKTUONEEMAKILDA ORGAANILISE AINE UURIMINE LÄMMASTIKHAPPELISE OKSUDATSIOONI TEEL}

Artiklis on esitatud alifaatsete mono-, di- ja benseenkarboksüülhapete koostised ja kogused, mis saadi diktüoneemakilda orgaanilise aine struktuuri uurimisel oksüdeeriva destruktsiooni teel lämmastikhappega. Pehme oksüdatsiooni (20\% HNOs, 1 ööpäev, toatemperatuur) produktides määrati looduses sagedamini esinevad paarisaatomilised küllastunud monokarboksüülhapped: müristiin-, palmitiin- ja steariinhape. Kilda oksüdeerimisel $\left(58 \% \mathrm{HNO}_{3}, 105^{\circ} \mathrm{C}, 3 \mathrm{~h}\right)$ saadi teise ordoviitsiumi põlevkivi, kukersiidiga võrreldes tunduvalt vähem karboksüülhappeid, kusjuures suhteliselt suur osatähtsus oli benseenkarboksüülhapetel $(16 \%)$. See viitab diktüoneemakilda ja kukersiidi orgaanilise aine tunduvale erinevusele.

\section{R. VESKI, N. FILIMONOVA, Eugenia EONDAR, T. LUMISTE, A. FOMINA}

\section{STUDY OF THE ORGANIC MATTER OF DICTYONEMA SHALE BY NITRIC OXIDATION}

In the mild oxidation products of dictyonema shale $\left(20 \% \mathrm{HNO}_{3}, 24 \mathrm{~h}\right.$, at room temperature) saturated monocarboxylic acids of frequent occurrence, viz. myristic, palmitic and stearic acids, were determined.

At the oxidation of dictyonema shale $\left(58 \% \mathrm{HNO}_{3}, 105^{\circ} \mathrm{C}, 3 \mathrm{~h}\right)$ considerably fewer carboxylic acids were obtained in comparison with kukersite, the other Ordovician oil shale, but the former consisted of benzene carboxylic acids $(16 \%)$. This is indicative of the differences between the organic matter of dictyonema shale and kukersite. 